\title{
Multiple immune-modulatory functions of cathelicidin host defense peptides
}

\author{
Ka-Yee (Grace) Choi and Neeloffer Mookherjee* \\ Department of Internal Medicine and Immunology, Manitoba Centre for Proteomics and Systems Biology, University of Manitoba, Winnipeg, MB, Canada \\ *Correspondence: mookherj@cc.umanitoba.ca
}

An essential function of innate immunity is initiating inflammatory responses to limit the spread of invading pathogens, followed by regulatory mechanisms aimed at resolving inflammation and returning the immune system to homeostasis. These meticulously regulated processes are triggered by various pathogen-associated molecular patterns or endogenous damage-associated molecular patterns. A group of natural peptides that have gained notoriety in recent years as immune-modulatory molecules contributing to both resolution of infections and inflammation, thus playing a role in maintaining homeostasis are host defense peptides (HDPs). These are gene-encoded cationic short peptides, less than 50 amino acids with an overall positive charge of +2 to +7 , and $\geq 30 \%$ of hydrophobic residues. The two most well characterized families of HDPs in mammals are cathelicidins and defensins. We will focus on cathelicidin HDPs in this review.

Genes encoding cathelicidin HDPs have a highly conserved N-terminal cathelin domain in their precursor protein (Tomasinsig and Zanetti, 2005). This conserved cathelin domain has helped in the discovery of new cathelicidins from diverse species including non-mammalian species such as chicken, trout, and hagfish. The biological active mature mammalian cathelicidin peptides are processed from their precursor protein by proteolytic cleavage by serine proteases, e.g., proteinase 3, elastase, and kallikrein (Shinnar et al., 2003; Morizane et al., 2010). The biologically active mature cathelicidins are diverse in their sequence and structure, and can be classified into four structural groups; amphipathic $\alpha$-helices (e.g., murine CRAMP), $\beta$-hairpin molecules (e.g., porcine protegrin 1), those with extended structures (e.g., bovine indolicidin), and cyclic peptides (e.g., bactenecin). Mammalian cathelicidins are found in granules of neutrophils as well as other cell types such as myeloid precursors, epithelial cells, mast cells, lymphocytes, and keratinocytes.
These peptides are expressed in a wide variety of tissues (oral cavity, skin, intestine, lungs, cervix, etc.) and found in body fluids such as plasma, breast milk, saliva, gastric juice, semen, sweat, and bronchoalveolar fluid (Nijnik and Hancock, 2009). The biologically active mature cathelicidin peptides have been demonstrated to mediate a wide range of activity from antimicrobial to immune-modulatory (discussed below). Some of the most well studied cathelicidins are human LL-37, murine CRAMP, bovine BMAP-28, and porcine PR-39.

\section{PROTECTION AGAINST INFECTIONS}

Decreased expression of cathelicidin HDPs has been associated with increased susceptibility to infections. For example, decreased expression of human cathelicidin LL-37 is linked to increased susceptibility to skin infections, frequent oral bacterial infections, severe periodontal disease, and cutaneous infections by the parasitic protozoan leishmania (Bowdish et al., 2005; Kulkarni et al., 2011). A recent study has demonstrated that the active metabolite of vitamin D induces the expression of LL-37 thus contributing to protection against tuberculosis (Jo, 2010). Similarly, the murine cathelicidin CRAMP is known to provide protection against streptococcus infections (Nizet et al., 2001). Thus, it is not surprising that research in this area was propelled by the interest of developing these peptides as alternate antibiotic-like therapy for infectious disease. However, it has been shown that the direct microbicidal activity of these peptides is often antagonized in the presence of physiological salt concentration, heparin, and serum factors (Bowdish et al., 2005). Also, microbial factors such as polysaccharides released by certain pulmonary bacterial pathogens antagonize the direct microbial killing property of these peptides (Benincasa et al., 2009). However, the fact remains that cathelicidins can indeed protect against a wide range of infections from bacteria, viruses, and parasites. As cathelicidins have been also demonstrated to stimulate both innate and adaptive immune responses (discussed below), the ability of cathelicidins to contribute to resolution of infections is now thought to be primarily due to their role in host immunity.

\section{ROLE IN IMMUNE-MEDIATED INFLAMMATORY DISORDERS}

Altered expressions of cathelicidins have also been reported in auto-inflammatory or auto-immune diseases. Human LL-37 is found to be suppressed in atopic dermatitis and Crohn's disease (Ong et al., 2002; Wehkamp et al., 2007), but shown to be elevated in systemic lupus erythematosus (SLE) and rheumatoid arthritis (Paulsen et al., 2002; Sun et al., 2011). It has been proposed that LL-37 can complex with self DNA activating dendritic cells to contribute to the pathogenesis of SLE (Lande et al., 2011). Whereas, in psoriasis it has been hypothesized that LL-37 can act both as an effector and a regulator (Kanda et al., 2010). Furthermore, a recent study has shown that LL-37 can interfere in the activation of inflammasome contributing to suppression of pro-inflammatory responses in psoriasis (Dombrowski et al., 2011). Consistent with this, it has been hypothesized that LL-37 can protect against auto-immune diseases, which may be in part mediated by vitamin D (Bartley, 2010). Even though studies have demonstrated that altered cathelicidin expression is associated with chronic inflammatory auto-immune diseases, clarification of their specific roles in immune-mediated inflammation will require further investigations. Research in the last decade has established that cathelicidins mediate a wide range of immune functions including promotion of barrier repairs, chemokine and cytokine production, modulation of dendritic cell differentiation, and T-cell polarization, as well as demonstrate potent anti-sepsis and anti-inflammatory properties (discussed below). Elucidating the differential effects 
of pro- and anti-inflammatory functions mediated by these peptides resulting in both immune activation and control of inflammation represents an exciting area of research.

\section{CATHELICIDIN-MEDIATED IMMUNE ACTIVATION}

A primary innate immune function mediated by cathelicidins is the facilitation of immune cell recruitment, either by direct chemoattractant properties or indirectly by inducing the production of chemokines. For example, human LL-37 and porcine PR-39 are direct chemoattractants for neutrophils, monocytes, T-cells, mast cells, etc. (Yang et al., 2001; Niyonsaba et al., 2002; Tjabringa et al., 2006). In addition, cathelicidins such as LL-37 can also promote chemotaxis by inducing the production of chemokines, e.g., MCP-1, RANTES, Gro- $\alpha$, and IL- 8 from both immune cells and other cell types such as epithelial cells and gingival fibroblasts (Mookherjee et al., 2006; Montreekachon et al., 2011). LL-37 also up-regulates the expression of chemokine receptors such as CXCR4, CCR2, and IL-8RB in macrophages (Scott et al., 2002). Mediating recruitment of leukocytes and thus aiding in phagocytosis to enhance clearance of pathogens is one of the critical innate immune functions of cathelicidin peptides. Furthermore, cathelicidins such as LL-37 synergistically enhances antiinfective immune responses in the presence of certain critical cytokines such as IL-1 $\beta$ and GM-CSF (Yu et al., 2007). Other innate immune activating properties of cathelicidins are (i) mediating protection against mycobacterium by promoting autophagy in macrophages (Yuk et al., 2009), (ii) prolonging the life span of neutrophils by inducing the expression of anti-apoptotic protein $\mathrm{BcL}-\mathrm{X}_{\mathrm{L}}$ and inhibiting caspase-3 activity, thus enhancing phagocytosis by neutrophils (Nagaoka et al., 2006), and (iii) enhancing epithelial wound healing (Carretero et al., 2008).

Cathelicidins such as human LL-37 appear to be a link between the innate and adaptive immune responses by influencing dendritic cell activiation and polarization of T-lymphocytes (Davidson et al., 2004; Bandholtz et al., 2006). LL-37 up-regulates the endocytic capacity of dendritic cells and enhances the secretion of cytokines that aid in the polarization of a Th1 immune response (Davidson et al., 2004). Apart from influencing the initiation of the adaptive immune response, recent studies have shown that cathelicidins also have a direct impact on lymphocytes. For example, murine CRAMP can directly alter Tand $\mathrm{B}$-cell responses, promote and regulate humoral and cellular antigen-specific adaptive immune responses (Kurosaka et al., 2005; Kin et al., 2011). Overall, cathelicidins have a direct effect on immune cells influencing both innate and adaptive immunity against pathogenic attack. Most of the above mentioned immunity-related activity mediated by cathelicidins can be described as pro-inflammatory functions required for resolution of infections. However, these peptides also exhibit anti-inflammatory properties, thus playing a significant role in balancing inflammation and maintaining homeostasis.

\section{CONTROL OF INFLAMMATION BY CATHELICIDINS}

Peptides such as LL-37 and CRAMP have been demonstrated to confer protection in animal models of pathogenic sepsis (Cirioni et al., 2006), and have anti-inflammatory effects in "sterile" inflammatory diseases such as ulcerative colitis (Wong et al., 2012). Consistent with this, cathelicidin knock out mice show increased inflammatory responses compared to wild type (Morioka et al., 2008). Recent studies have also shown that synthetic cationic peptides derived from cathelicidins can indeed suppress inflammation in infection models (Scott et al., 2007) and in immune-mediated inflammatory models (Turner-Brannen et al., 2011).

Mechanistic studies have demonstrated that cathelicidins intervene at multiple points within the inflammatory cascade to suppress inflammation in a targeted fashion. For example, human and bovine cathelicidins alter the TLR-to-NF- $\kappa B$ pathway in the presence of exogenous inflammatory stimuli (e.g., endotoxin) and selectively suppress specific pro-inflammatory cellular responses such as TNF- $\alpha$, TNFAIP2, IL- $1 \beta$, and NFאB1 (Mookherjee et al., 2006). In contrast, anti-inflammatory mediators such as IL-10, TNFAIP3, NF- $\kappa B$ inhibitor NFאBIA are enhanced by these peptides (Mookherjee et al., 2006; Brown et al., 2011). It has also been shown that LL-37 can inhibit cellular immune responses triggered by IFN $-\gamma$, which is a key cytokine for polarization of Th1-responses (Nijnik et al., 2009). Another mechanism of inflammatory control demonstrated for cathelicidin peptides, e.g., PR-39, is by proteosome-mediated degradation of I $\mathrm{K} \mathrm{B} \alpha$ and subsequent inhibition of activation of NF- $\kappa B$ (Bao et al., 2001).

Intracellular uptake has been shown to be important for immunomodulatory activity of cathelicidins (Lau et al., 2005). This is mediated either by putative surface receptors (De et al., 2000; Lau et al., 2005) or by atypical endocytic pathways followed by interaction with intracellular receptor, e.g., GAPDH (Mookherjee et al., 2009). Specific receptor interaction for cathelicidin peptides and how this influences different immune-modulatory functions is yet to be completely resolved. The molecular mechanism of the anti-inflammatory activity of cathelicidins appears to be very complex, requires intracellular uptake, interaction with either putative surface or intracellular receptors, leading to the alteration of various signaling pathways (e.g., NF- $\kappa B$, p38 and JNK MAPK, PI3K) with different kinetics.

The overall result of immunomodulatory functions of cathelicidin HDPs is the net balancing or control of inflammation without compromising immune responses that are required for resolution of infections. This duality or pro- and antiinflammatory biological activities of these peptides has made them attractive agents to be explored as therapeutics. The distinct advantages of developing cathelicidins and their derivatives as therapeutics are (i) the ability to control inflammation without compromising the immune functions required to clear infections, and (ii) the unlikelihood of developing microbial resistances against these peptides, since most of these peptides influence the immune system under physiological conditions to control infections rather than direct microbicidal activity (Afacan et al., 2012).

\section{SUMMARY}

Cathelicidins have been defined to play multiple roles in immunity contributing to both resolution of infections and inflammation. The molecular mechanisms governing the multiple functions of these peptides in immunity is very complex, involving various signaling pathways and multiple transcription factors, and is influenced by 
the cellular environment and extracellular signals. Moreover, the process of endocytic uptake or interaction with specific receptors and how this mediates the diverse immunomodulatory functions of cathelicidins is not completely understood. However, evidence in the last decade revealing the duality of pro- and anti-inflammatory functions of cathelicidins, resulting in the promotion of immune responses required for resolution of infections and at the same time controlling inflammation, has captured the interest of biomedical researchers. Consequently, there has been a keen interest in the development of these peptides, in particular their synthetic derivatives as therapeutics; as antimicrobials, anti-inflammatory agents, adjuvants, and in wound healing. The challenges however are limited pharmacokinetic or toxicology data, bioavailability, and high manufacturing costs. Establishing the immune-regulatory properties of HDPs such as cathelicidins and exploring their potential as immunomodulatory therapeutics represents an exciting avenue of research that is growing rapidly.

\section{ACKNOWLEDGMENTS}

Neeloffer Mookherjee is supported by Health Sciences Centre Foundation (Manitoba, Canada) and the Manitoba Health Research Council (MHRC) for peptide research.

\section{REFERENCES}

Afacan, N. J., Yeung, A. T., Pena, O. M., and Hancock, R. E. (2012). Therapeutic potential of host defense peptides in antibiotic-resistant infections. Curr. Pharm. Des. 18, 807-819.

Bandholtz, L., Ekman, G. J., Vilhelmsson, M., Buentke, E., Agerberth, B., Scheynius, A., and Gudmundsson, G. H. (2006). Antimicrobial peptide LL-37 internalized by immature human dendritic cells alters their phenotype. Scand. J. Immunol. 63, 410-419.

Bao, J., Sato, K., Li, M., Gao, Y., Abid, R., Aird, W., Simons, M., and Post, M. J. (2001). PR-39 and PR-11 peptides inhibit ischemia-reperfusion injury by blocking proteasome-mediated I kappa B alpha degradation. Am. J. Physiol. Heart Circ. Physiol. 281, H2612-H2618.

Bartley, J. (2010). Vitamin D: emerging roles in infection and immunity. Expert Rev. Anti. Infect. Ther. 8 , 1359-1369.

Benincasa, M., Mattiuzzo, M., Herasimenka, Y., Cescutti, P., Rizzo, R., and Gennaro, R. (2009). Activity of antimicrobial peptides in the presence of polysaccharides produced by pulmonary pathogens. J. Pept. Sci. 15, 595-600.

Bowdish, D. M., Davidson, D. J., Lau, Y. E., Lee, K., Scott, M. G., and Hancock, R. E. (2005). Impact of LL-37 on anti-infective immunity. J. Leukoc. Biol. 77, 451-459.

Brown, K. L., Poon, G. F., Birkenhead, D., Pena, O. M., Falsafi, R., Dahlgren, C., Karlsson, A., Bylund, J.,
Hancock, R. E., and Johnson, P. (2011). Host defense peptide LL-37 selectively reduces proinflammatory macrophage responses. J. Immunol. 186, 5497-5505.

Carretero, M., Escamez, M. J., Garcia, M., Duarte, B. Holguin, A., Retamosa, L., Jorcano, J. L., Rio, M. D., and Larcher, F. (2008). In vitro and in vivo wound healing-promoting activities of human cathelicidin LL-37. J. Invest. Dermatol. 128, 223-236.

Cirioni, O., Giacometti, A., Ghiselli, R., Bergnach, C., Orlando, F., Silvestri, C., Mocchegiani, F., Licci, A., Skerlavaj, B., Rocchi, M., Saba, V., Zanetti, M., and Scalise, G. (2006). LL-37 protects rats against lethal sepsis caused by gram-negative bacteria. Antimicrob. Agents Chemother. 50, 1672-1679.

Davidson, D. J., Currie, A. J., Reid, G. S., Bowdish, D. M., Macdonald, K. L., Ma, R. C., Hancock, R. E., and Speert, D. P. (2004). The cationic antimicrobial peptide LL-37 modulates dendritic cell differentiation and dendritic cell-induced T cell polarization. J. Immunol. 172, 1146-1156.

De, Y., Chen, Q., Schmidt, A. P., Anderson, G. M., Wang, J. M., Wooters, J., Oppenheim, J. J., and Chertov, O. (2000). LL-37, the neutrophil granule- and epithelial cell-derived cathelicidin, utilizes formyl peptide receptor-like 1 (FPRL1) as a receptor to chemoattract human peripheral blood neutrophils, monocytes, and T cells. J. Exp. Med. 192, 1069-1074.

Dombrowski, Y., Peric, M., Koglin, S., Kammerbauer, C., Goss, C., Anz, D., Simanski, M., Glaser, R., Harder, J., Hornung, V., Gallo, R. L., Ruzicka, T., Besch, R., and Schauber,J. (2011). Cytosolic DNA triggers inflammasome activation in keratinocytes in psoriatic lesions. Sci. Transl. Med. 3, 82ra38.

Jo, E. K. (2010). Innate immunity to mycobacteria: vitamin D and autophagy. Cell. Microbiol. 12, 1026-1035.

Kanda, N., Ishikawa, T., Kamata, M., Tada, Y., and Watanabe, S. (2010). Increased serum leucine, leucine-37 levels in psoriasis: positive and negative feedback loops of leucine, leucine-37 and pro- or anti-inflammatory cytokines. Hum. Immunol. 71, 1161-1171.

Kin, N. W., Chen, Y., Stefanov, E. K., Gallo, R. L., and Kearney, J. F. (2011). Cathelin-related antimicrobial peptide differentially regulates $\mathrm{T}$ - and B-cell function. Eur. J. Immunol. 41, 3006-3016.

Kulkarni, M. M., Barbi, J., Mcmaster, W. R., Gallo, R. L., Satoskar,A. R., and Mcgwire, B.S. (2011). Mammalian antimicrobial peptide influences control of cutaneous Leishmania infection. Cell. Microbiol. 13, 913-923.

Kurosaka, K., Chen, Q., Yarovinsky, F., Oppenheim, J. J., and Yang, D. (2005). Mouse cathelin-related antimicrobial peptide chemoattracts leukocytes using formyl peptide receptor-like 1 /mouse formyl peptide receptor-like 2 as the receptor and acts as an immune adjuvant. J. Immunol. 174, 6257-6265.

Lande, R., Ganguly, D., Facchinetti, V., Frasca, L., Conrad, C., Gregorio, J., Meller, S., Chamilos, G., Sebasigari, R., Riccieri, V., Bassett, R., Amuro, H., Fukuhara, S., Ito, T., Liu, Y. J., and Gilliet, M. (2011). Neutrophils activate plasmacytoid dendritic cells by releasing self-DNApeptide complexes in systemic lupus erythematosus. Sci. Transl. Med. 3, 73ra19.

Lau, Y. E., Rozek, A., Scott, M. G., Goosney, D. L., Davidson, D. J., and Hancock, R. E. (2005). Interaction and cellular localization of the human host defense peptide LL-37 with lung epithelial cells. Infect. Immun 73, 583-591.

Montreekachon, P., Chotjumlong, P., Bolscher, J. G., Nazmi, K., Reutrakul, V., and Krisanaprakornkit, S.
(2011). Involvement of $\mathrm{P} 2 \mathrm{X}(7)$ purinergic receptor and MEK1/2 in interleukin- 8 up-regulation by LL-37 in human gingival fibroblasts. J. Periodont. Res. 46, 327-337.

Mookherjee, N., Brown, K. L., Bowdish, D. M., Doria, S., Falsafi, R., Hokamp, K., Roche, F. M., Mu, R., Doho, G. H., Pistolic, J., Powers, J. P., Bryan, J., Brinkman, F. S., and Hancock, R. E. (2006). Modulation of the TLR-mediated inflammatory response by the endogenous human host defense peptide LL-37. J. Immunol. 176, 2455-2464.

Mookherjee, N., Lippert, D. N., Hamill, P., Falsafi, R., Nijnik, A., Kindrachuk, J., Pistolic, J., Gardy, J., Miri, P., Naseer, M., Foster, L. J., and Hancock, R. E. (2009). Intracellular receptor for human host defense peptide LL-37 in monocytes. J. Immunol. 183, 2688-2696.

Morioka, Y., Yamasaki, K., Leung, D., and Gallo, R. L. (2008). Cathelicidin antimicrobial peptides inhibit hyaluronan-induced cytokine release and modulate chronic allergic dermatitis. J. Immunol. 181, 3915-3922.

Morizane, S., Yamasaki, K., Kabigting, F. D., and Gallo, R. L. (2010). Kallikrein expression and cathelicidin processing are independently controlled in keratinocytes by calcium, vitamin $\mathrm{D}(3)$, and retinoic acid. J. Invest. Dermatol. 130, 1297-1306.

Nagaoka, I., Tamura, H., and Hirata, M. (2006). An antimicrobial cathelicidin peptide, human CAP18/LL-37, suppresses neutrophil apoptosis via the activation of formyl-peptide receptor-like 1 and $\mathrm{P} 2 \times 7$. J. Immunol. 176, 3044-3052.

Nijnik, A., and Hancock, R. E. (2009). The roles of cathelicidin LL-37 in immune defences and novel clinical applications. Curr. Opin. Hematol. 16, 41-47.

Nijnik, A., Pistolic, J., Wyatt, A., Tam, S., and Hancock, R. E. (2009). Human cathelicidin peptide LL-37 modulates the effects of IFN-gamma on APCs. J. Immunol. 183, 5788-5798.

Niyonsaba, F., Iwabuchi, K., Someya, A., Hirata, M., Matsuda, H., Ogawa, H., and Nagaoka, I. (2002). A cathelicidin family of human antibacterial peptide LL-37 induces mast cell chemotaxis. Immunology 106, 20-26.

Nizet, V., Ohtake, T., Lauth, X., Trowbridge, J., Rudisill, J., Dorschner, R. A., Pestonjamasp, V., Piraino, J., Huttner, K., and Gallo, R. L. (2001). Innate antimicrobial peptide protects the skin from invasive bacterial infection. Nature 414, 454-457.

Ong, P. Y., Ohtake, T., Brandt, C., Strickland, I., Boguniewicz, M., Ganz, T., Gallo, R. L., and Leung, D.Y. (2002). Endogenous antimicrobial peptides and skin infections in atopic dermatitis. N. Engl. J. Med. 347, 1151-1160.

Paulsen, F., Pufe, T., Conradi, L., Varoga, D., Tsokos, M., Papendieck, J., and Petersen, W. (2002). Antimicrobial peptides are expressed and produced in healthy and inflamed human synovial membranes. J. Pathol. 198, 369-377.

Scott, M. G., Davidson, D. J., Gold, M. R., Bowdish, D., and Hancock, R. E. (2002). The human antimicrobial peptide LL-37 is a multifunctional modulator of innate immune responses. J. Immunol. 169, 3883-3891.

Scott, M. G., Dullaghan, E., Mookherjee, N., Glavas, N., Waldbrook, M., Thompson,A., Wang,A.,Lee, K., Doria, S., Hamill, P., Yu, J. J., Li, Y., Donini, O., Guarna, M. M., Finlay, B. B., North, J. R., and Hancock, R. E. (2007). An anti-infective peptide that selectively modulates the innate immune response. Nat. Biotechnol. 25, 465-472.

Shinnar, A. E., Butler, K. L., and Park, H. J. (2003). Cathelicidin family of antimicrobial peptides: pro- 
teolytic processing and protease resistance. Bioorg. Chem. 31, 425-436.

Sun, C. L., Zhang, F. Z., Li, P., and Bi, L. Q. (2011). LL-37 expression in the skin in systemic lupus erythematosus. Lupus 20, 904-911.

Tjabringa, G. S., Ninaber, D. K., Drijfhout, J. W., Rabe, K. F., and Hiemstra, P. S. (2006). Human cathelicidin LL-37 is a chemoattractant for eosinophils and neutrophils that acts via formyl-peptide receptors. Int. Arch. Allergy Immunol. 140, 103-112.

Tomasinsig, L., and Zanetti, M. (2005). The cathelicidins -structure, function and evolution. Curr. Protein Pept. Sci. 6, 23-34.

Turner-Brannen, E., Choi, K. Y., Lippert, D. N., Cortens, J. P., Hancock, R. E., El-Gabalawy, H., and Mookherjee, N. (2011). Modulation of interleukin-1beta-induced inflammatory responses by a synthetic cationic innate defence regulator peptide, IDR-1002, in synovial fibroblasts. Arthritis Res. Ther. 13, R129.
Wehkamp, J.,Schmid,M., and Stange, E. F. (2007).Defensins and other antimicrobial peptides in inflammatory bowel disease. Curr. Opin. Gastroenterol. 23, 370-378.

Wong, C. C., Zhang, L., Li, Z. J., Wu, W. K., Ren, S. X., Chen, Y.C., Ng, T.B., and Cho, C.H. (2012). Protective effects of cathelicidin-encoding Lactococcus lactis in murine ulcerative colitis. J. Gastroenterol. Hepatol. doi: 10:1111/ j1440-1746.2012.07158x. [Epub ahead of print].

Yang, D., Chertov, O., and Oppenheim, J. J. (2001). Participation of mammalian defensins and cathelicidins in anti-microbial immunity: receptors and activities of human defensins and cathelicidin (LL37). J. Leukoc. Biol. 69, 691-697.

Yu, J., Mookherjee, N., Wee, K., Bowdish, D. M., Pistolic, J., Li, Y., Rehaume, L., and Hancock, R. E. (2007). Host defense peptide LL-37, in synergy with inflammatory mediator IL-1beta, augments immune responses by multiple pathways. J. Immunol. 179, 7684-7691.
Yuk, J. M., Shin, D. M., Lee, H. M., Yang, C. S., Jin, H. S., Kim, K. K., Lee, Z. W., Lee, S. H., Kim, J. M., and Jo, E. K. (2009). Vitamin D3 induces autophagy in human monocytes/macrophages via cathelicidin. Cell Host Microbe 6, 231-243.

Received: 11 May 2012; accepted: 22 May 2012; published online: 11 June 2012.

Citation: Choi KY and Mookherjee N (2012) Multiple immune-modulatory functions of cathelicidin host defence peptides. Front. Immun. 3:149. doi:10.3389/ fimmu.2012.00149

This article was submitted to Frontiers in Molecular Innate Immunity, a specialty of Frontiers in Immunology. Copyright (C) 2012 Choiand Mookherjee. This is an open-access article distributed under the terms of the Creative Commons Attribution Non Commercial License, which permits noncommercial use, distribution, and reproduction in other forums, provided the original authors and source are credited. 